\title{
Comparison of European bearing capacity calculation methods for shallow foundations
}

\section{J.-G. Sieffert and C. Bay-Gress}

\section{G. T. Houlsby and B.W. Byrne, Oxford University}

The authors are to be congratulated on their compilation of existing practice for bearing capacity calculations in Europe. We find it disappointing, however, that all of these treat the problem of combined loading within what we would regard as an old-fashioned approach. The paper follows the practice in which a combination of vertical, moment and horizontal $(\boldsymbol{V}, \boldsymbol{M}$, $\boldsymbol{H})$ loading is treated as a single load, inclined to the vertical at $\delta=\tan ^{-1}(\boldsymbol{H} / \boldsymbol{V})$, of magnitude $\sqrt{\boldsymbol{V}^{2}+\boldsymbol{H}^{2}}$ and eccentricity $e=\boldsymbol{M} / \boldsymbol{V}$. Much of the early published work (notably that of Meyerhof, Hansen and Vesic as cited in the paper) adopts this approach, and this has been followed in European practice. The moment (or eccentricity) is allowed for by adopting the 'effective area' approach, and the inclination is treated by introducing a set of semi-empirical 'inclination factors' on each of the terms in the conventional bearing capacity expression.

In our view a more enlightening approach is to express the interaction between vertical, moment and horizontal loads through the use of a yield surface in $(\boldsymbol{V}, \boldsymbol{M}, \boldsymbol{H})$ space. An example would be:

$$
\begin{aligned}
f= & \left(\frac{\boldsymbol{M}}{m_{0} B \boldsymbol{V}_{0}}\right)^{2}+\left(\frac{\boldsymbol{H}}{h_{0} \boldsymbol{V}_{0}}\right)^{2}+\frac{e \boldsymbol{M} \boldsymbol{H}}{m_{0} h_{0} B \boldsymbol{V}_{0}^{2}} \\
& -\left(\frac{\boldsymbol{V}}{\boldsymbol{V}_{0}}\right)^{2}\left(1-\frac{\boldsymbol{V}}{\boldsymbol{V}_{0}}\right)^{2}=0
\end{aligned}
$$

which is expressed in terms of four simple constants. The value of $V_{0}$ is the bearing capacity under purely vertical loading, and would be calculated by conventional methods. The dimensionless factors $m_{0}$ and $h_{0}$ define the maximum moment and horizontal capacities as $m_{0} B \boldsymbol{V}_{0}$ and $h_{0} \boldsymbol{V}_{0}$ respectively. Finally, $e$ is a factor which allows for interactions between moment and horizontal loading, recognizing that (for instance) if the horizontal load is from left to right, then a clockwise moment has a different effect from an anticlockwise one.

The yield surface approach to this type of problem has a long history, having been introduced by Roscoe and Schofield. ${ }^{14}$ It was used by Butterfield and Ticof ${ }^{15}$ and recently in much research work on combined loading. ${ }^{16-19}$ It is common in offshore engineering practice to express bearing capacity calculations in the form of a yield surface (even if the shapes are derived from the Hansen or Vesic formulae). The recom- mended practice for jack-up unit assessment, ${ }^{20}$ for instance, uses this approach.

What are the advantages of the yield surface approach? Firstly, by expressing the results using the terminology of plasticity theory, it brings bearing capacity calculations firmly into the mainstream of engineering mechanics calculations, rather than expressing them as rather unusual ad hoc procedures. Secondly, it allows the issue of displacements at yield to be addressed (by defining either an 'associated', or more realistically a 'nonassociated' flow rule as well as the yield surface). Thirdly, it gets away from the idea of bearing capacity being purely an issue of failure and instead addresses it as one of yield. In many circumstances this yield results in hardening behaviour (expansion of the yield surface), accompanied by substantial plastic deformation (settlements).

It is our hope that if a similar comprehensive review of European practice were to be carried out in the future, that the description of the bearing capacity problem in terms of yield surfaces would have become common practice.

\section{Author's reply}

The authors thank G. T. Houlsby and B. W. Byrne for their interest in the paper. We are completely in agreement with them concerning the interest to use a yield surface in (V, M, H) space. Of course, we know the papers given in references, and we are enlarging our research works in this way. ${ }^{1-3}$

The aim of our paper was not to give a State of Art of the bearing capacity calculation methods, but to give a State of Practice in Europe using the basic Terzaghi's formulation-the comments confirm the accuracy of the described practices - in order to prove the very large differences between various countries, and the necessity of a common detailed European Standard as underlined by Andrew Bond in his Editorial.

\section{REFERENCES}

14. Roscoe K. H. and Schofield A. N. The stability of short pier foundations on sand. Discussion. British Welding Journal, 1957, Jan., 12-18.

15. ButTERFIELD R. and Ticof J. Design parameters for granular soils. Discussion. Proceedings of the 7th International Conference on Soil Mechanics and Foundation Engineering, Brighton, 1979, 4, 259-261. 
16. Nova R. and Montrasio L. Settlements of shallow foundations on sand. Géotechnique, 1991, 41, No. 2, 243-256.

17. Martin C. M. and Houlsby G. T. Combined loading of spudcan foundations on clay: laboratory tests. Géotechnique (in press).

18. ButTeRFIELD R. and GotTARDI G. A complete three-dimensional failure envelope for shallow footings on sand. Géotechnique, 1994, 44, No. 1, 181-184.
19. GotTardi G., Houlsby G. T. and Butterfield R. The plastic response of circular footings on sand under general planar loading. Géotechnique, 1999, 49, No. 4, 453-470.

20. Society of Naval Architects and Marine Engineers. Guidelines for Site Specific Assessment of Mobile Jack-up Units. New Jersey, 1994, SNAME, Technical and Research Bulletin 5-5A. 